\title{
Inverted roof insulation kits and their durability
}

\author{
Barbara Francke ${ }^{1,{ }^{*}}$, and Robert Geryło ${ }^{1}$ \\ ${ }^{1}$ Building Research Institute, Filtrowa 1, 00-611 Warsaw, Poland
}

\begin{abstract}
In the paper there was analyzed a mechanism of loss of performance properties of inverted roof insulation kits resulted by moisture increase of the insulation layers. This problem is very important in such systems because the thermal insulation is placed above the waterproofing layer and is not protected against water absorption. Abovementioned problem is more and more common in the course of building's utilization in Polish climate conditions. Because inverted roof kits are based on extruded polystyrene (XPS) and expanded polystyrene (EPS), those materials have been used in tested samples. The results of laboratory tests showed the phenomenon and its effect on durability and sustainability of roof covering performance. It was also found that the biggest influence on the increase of moisture in the thermal insulation layer has not the long term water absorption by immersion but freeze - thaw cycles.
\end{abstract}

\section{Introduction}

Roof and terrace are parts of external building envelope which close building or its fragment from above and which act as a ceiling and roof in structural and functional aspect, i.e. it transfers external loads and protects the building space against changes of microclimate, rainfall and weather influences. Roofs may be constructed in a traditional layout, in which the roof coverings are placed over thermal insulation, as well as using an inverted layer system, in which the layer sequence is reversed. In inverted roofing systems, the thermal insulation, loaded with surface protection layers (ballast or parking decks), is placed loosely on the waterproofing layer and is therefore exposed to weather, especially rainfall. That is the reason why the inverted roof kits require the use of insulation materials which[1,2]:

- do not absorb water,

- are resistant to repeated freeze and thaw cycles,

- have very good thermal resistance properties,

- have high compressive strength,

- are resistant to biological corrosion,

i.e. fulfill the basic role of thermal insulation, which is to reduce the loss of heat through building's envelope.

According to ETAG 031[2], materials suitable for use in inverted roof kits are both extruded polystyrene (XPS) and expanded polystyrene (EPS); using XPS is decadal tradition, while EPS has been utilized since recent years and publications point out insufficient experience in that regard $[2,3]$.

\footnotetext{
* Corresponding author: b.francke@itb.pl
} 
Recent inspections of inverted roofs show more and more frequent reveal of dampness of the thermal insulation made of materials the absorption of which is theoretically low (i.e. $<3 \%$ ). According to common knowledge of the civil engineering community, which is however unsupported by official requirements and normative documents, these products should guarantee the necessary thermal insulation of the roofing throughout the building's working life. These assumptions are not always reflected in real life conditions, where after only several years of usage, considerable dampness can be noticed in the insulating material, which adversely affects its basic function of providing heat insulation to the rooms under the roof $[4,5,6,7]$.

Calculations of the thermal conductivity of construction barriers take into account modifiers due to air spaces in the insulation layer, mechanical fasteners that perforate the insulation material and, in case of inverted roofs, also influence of rainfall, as with this solution rainwater may flow under the insulation, causing periodic increase of heat transfer. The value of the index describing relative increase in thermal conductivity of materials used in inverted kits is shown in fig. 1[8], and values of the thermal conductivity in relation to moisture content - in fig. 2[8]. Graphs show that with excessive levels of moisture, the heat resistance properties drop considerably.

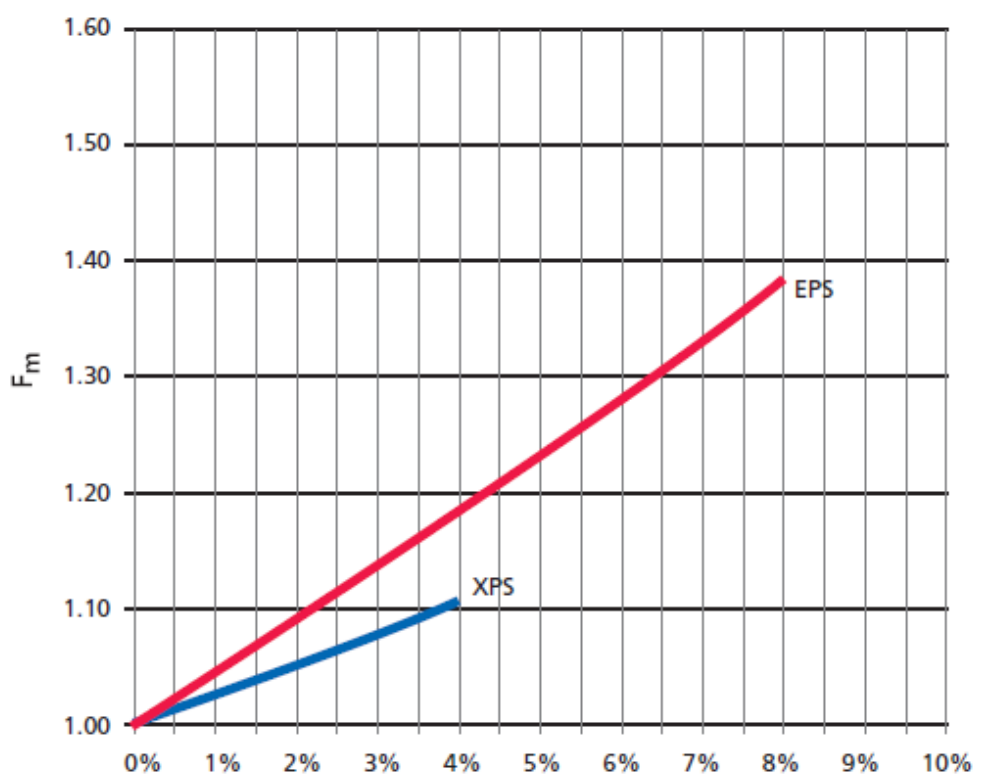

Fig. 1. Thermal conductivity change depending on product's moisture content [8]. 


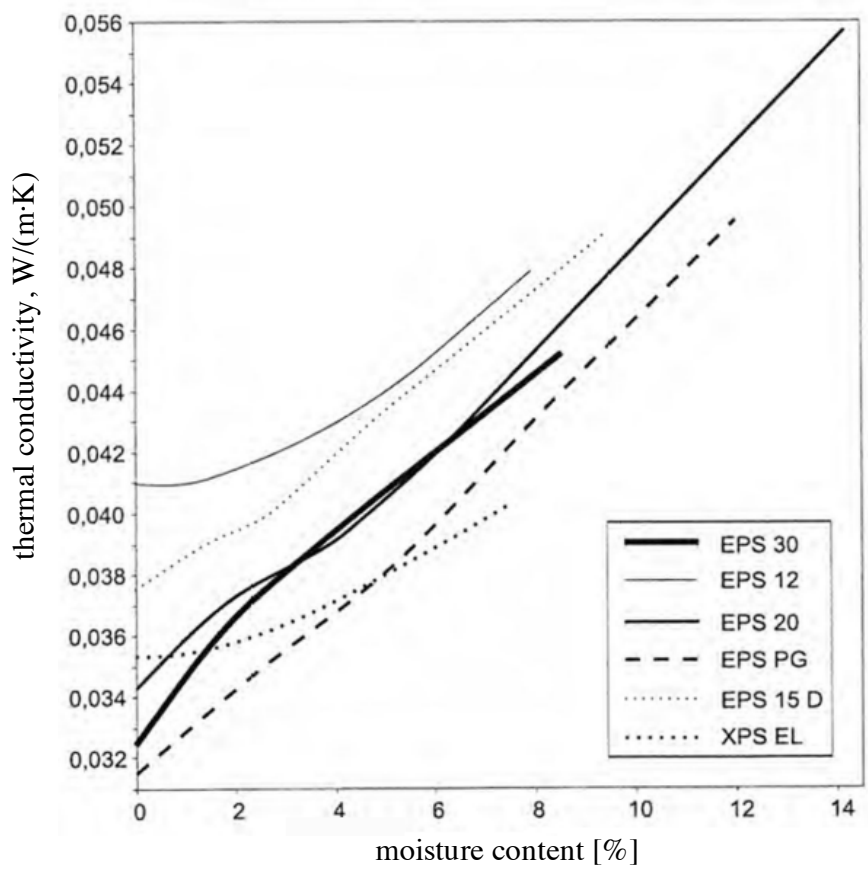

Fig. 2. Change of thermal conductivity depending on product's moisture content[8]

So far, technical literature does not report information supported by tests which would describe the mechanism of water absorption by thermal insulation products commonly of low absorption if they are used in inverse roofing. Another regarded as not profoundly explored issue is the problem of their resistance to frost, which results in increase of moisture content coupled with a small drop in strength, as well as the influence of these factors on durability of thermal resistance after freeze-thaw cycles.

\section{Experimental program}

The Building Research Institute started research of the above phenomenon in 2014-2017 in order to find an explanation for this issue. The research was carried out in two parallel paths, i.e.

$>$ in laboratory conditions and on a test roof; tests used new materials purchased for the purposes of this research. As part of the laboratory tests an attempt was made to:

a) explain which service factor has the greatest influence on the rate of increase in moisture content of the insulation material, based on accelerated aging in laboratory conditions,

b) determine the relation between increase in moisture content of the insulation material and the thermal conductivity values,

in buildings used for years, where dampness problems were diagnosed in insulation used for inverted roofs/terraces.

Materials used in the tests were:

- perimeter shape-moulded EPS boards with a profiled surface (compliant with standard PN-EN 13163),

- smooth-skin XPS boards (compliant with standard PN-EN 13164).

Their basic characteristics are given in table 1 . 
Table 1. Basic characteristics of EPS and XPS boards used in the research

\begin{tabular}{|c|c|c|c|c|}
\hline $\begin{array}{l}\text { Specimen } \\
\text { label }\end{array}$ & Board type & $\begin{array}{c}\text { Thickness, } \\
\text { mm }\end{array}$ & $\begin{array}{c}\text { Apparent } \\
\text { density, } \\
\mathbf{k g} / \mathrm{m}^{3}\end{array}$ & $\begin{array}{l}\text { Compressive stress at } \\
10 \% \text { deformation, } \mathrm{kPa}\end{array}$ \\
\hline EPS 1 & EPS 200 & 50 & 31 & 215 \\
\hline EPS 2 & EPS 120 & 50 & 21 & 128 \\
\hline EPS 3 & EPS 100 & 50 & 18 & 99 \\
\hline EPS 4 & EPS 120 & 50 & 21 & 130.9 \\
\hline EPS 5 & EPS 120 & 60 & 22 & 143.3 \\
\hline EPS 6 & EPS 200 & 65 & 32 & 235.8 \\
\hline EPS 7 & EPS 120 & 80 & 22 & 146.5 \\
\hline XPS I & XPS 300 & 40 & 33 & 453 \\
\hline XPS II & XPS 300 & 100 & 34 & 362 \\
\hline XPS III & XPS 500 & 100 & 34 & 533.3 \\
\hline XPS IV & XPS 500 & 100 & 32 & 503.9 \\
\hline
\end{tabular}

\section{Results}

The research work started with long-term total immersion of the EPS and XPS boards in water for 28 days (in accordance with PN-EN 12087:2013-07). Wet samples were then subjected to 300 freeze-thaw cycles (in accordance with PN-EN 12091:2013-07). The results of these tests are presented in fig. 3 and 4 . Indirect measurements of water absorption taken after 7 and 14 days of immersion showed that both in the case of XPS and EPS the most considerable increase of moisture content takes place in the first days. With time, the absorption rate decreases. Irrespective of the initial absorption after 28 days of immersion, after 300 freeze-thaw cycles the moisture content of the EPS and XPS rises significantly. With moisture levels recorded after immersion in water reaching: for EPS boards in the range of $0.2 \div 0.4 \%$ and for XPS boards $0.3 \div 0.5 \%$, the final absorption resulting from the effect the freeze-thaw cycles had on the soaked samples was $7.3 \div 25.7 \%$ for EPS and $7.6 \div 21.3 \%$ for XPS. Test results confirmed that there is no direct relation between the absorption of insulation boards after long-term immersion in water and the effects of freeze-thaw cycles. Tested products show different ability to absorb water at over zero temperatures than in a situation of temperatures fluctuating from over to below zero. 


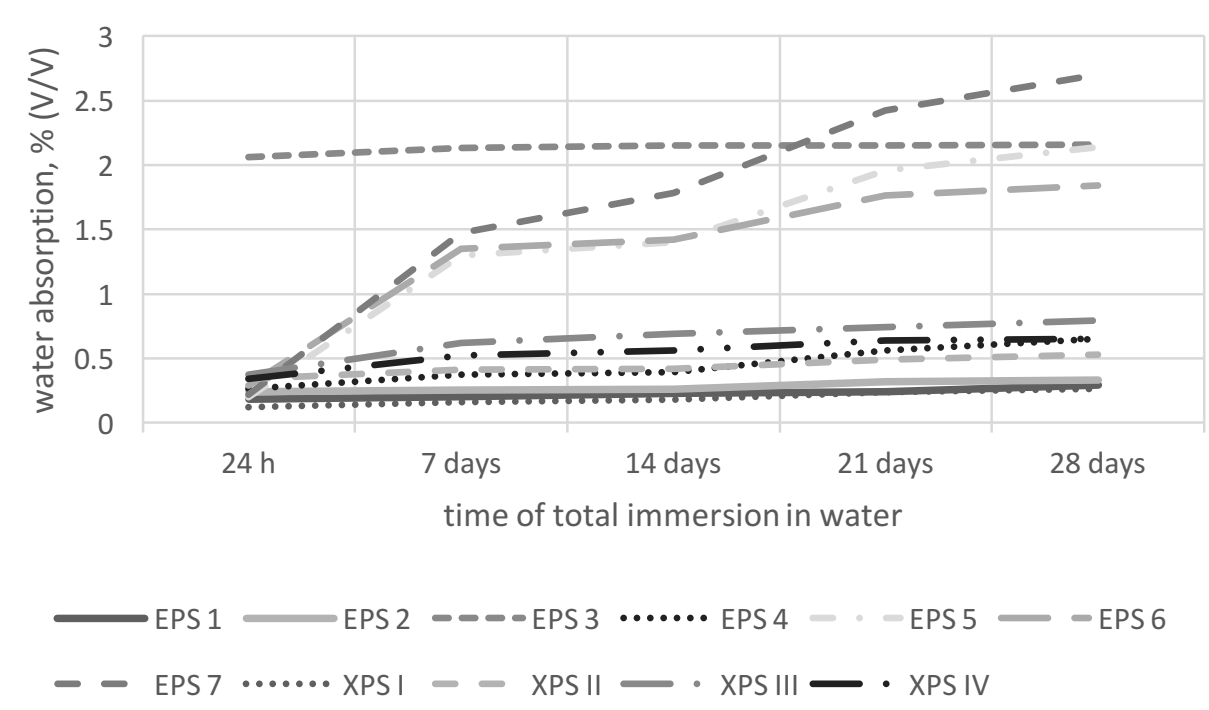

Fig. 3. Increase in water absorption as a result of long-term immersion of EPS and XPS boards over time.

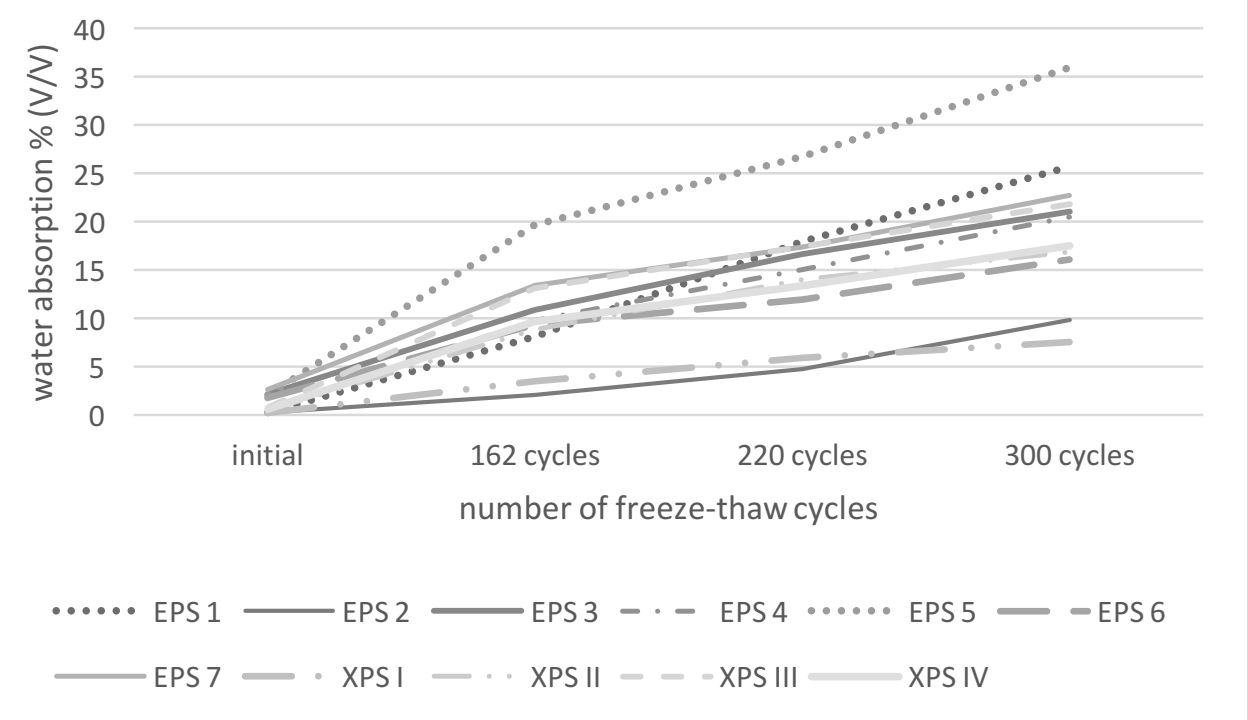

Fig. 4. The change of moisture content of EPS and XPS boards pre-soaked through immersion in water over 28 days, after subsequently being subjected to freeze-thaw cycles.

The observations so far allow to additionally conclude that the assessment of the boards' ability to absorb water only based on testing the long-term immersion in water does not yield a clear answer regarding preserving the characteristics of insulation materials used for roofs and terraces with inverted layering despite the fact that such assumption is adopted in current product standards, i.e. PN-EN 13163 and PN-EN 13164. According to assumptions in the above mentioned documents, only the change in compressive stress at $10 \%$ deformation is assessed after the freeze-thaw cycles, without evaluating the thermal aging effect on the boards' absorption. Due to the fact that the moisture content of the samples has direct impact 
on the material's thermal conductivity, this assumption does not allow to fully assess the product intended for use in roofs/terraces with an inverted roofing system. Fig. 5 shows the change in thermal conductivity for EPS and XPS boards subjected to accelerated aging in laboratory conditions (i.e. immersion in water over 28 days, then subjecting to 300 freezethaw cycles) as compared to the air-dry product (the new as well as the one after being subjected to the aforementioned aging processes and dried).

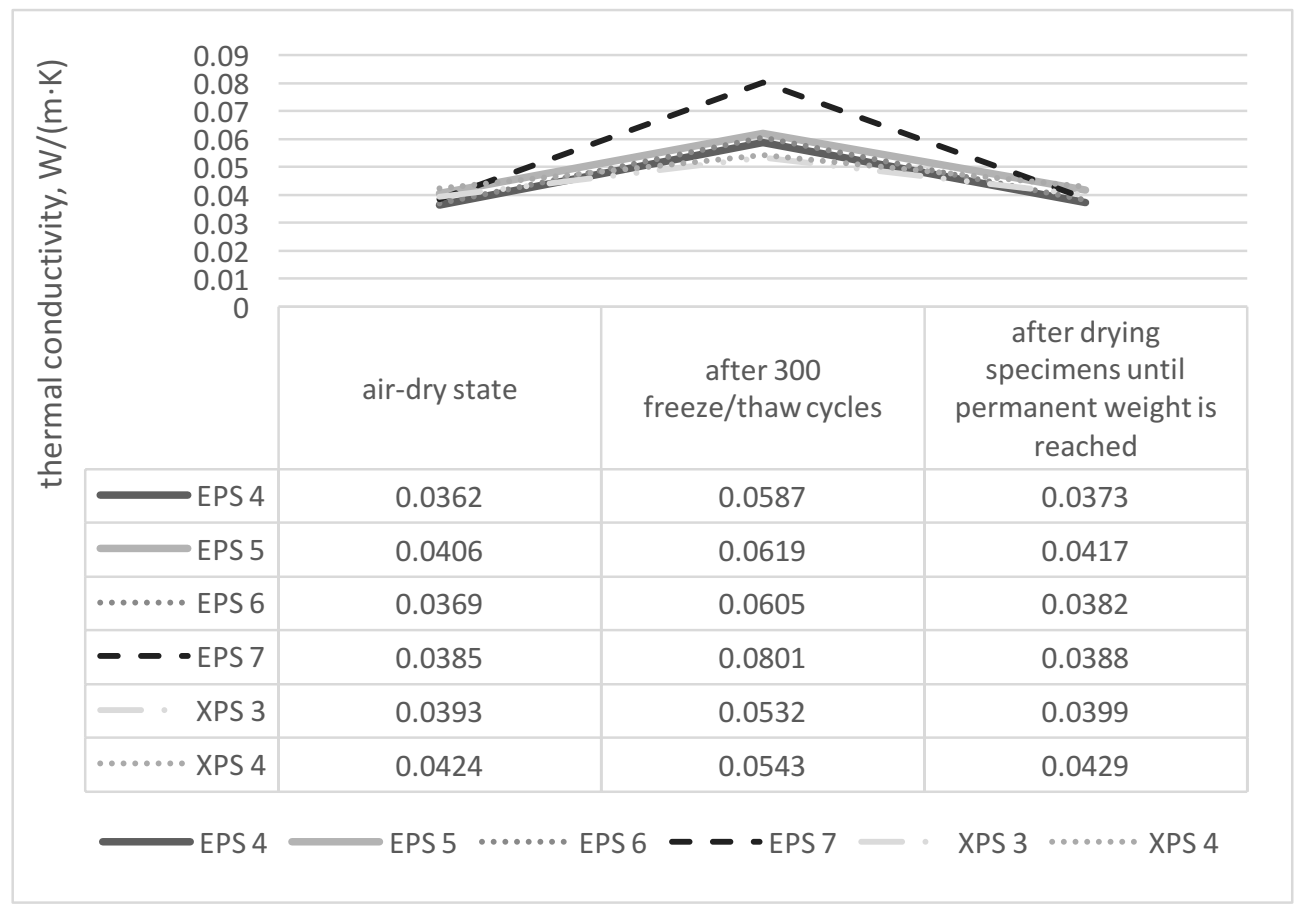

Fig. 5. Change in thermal conductivity for selected EPS and XPS boards after accelerated aging consisting in immersion in water over 28 days and 300 freeze-thaw cycles as compared to the air-dry product.

Obtained test results allow to conclude that moisture content has considerable impact on the $\lambda$ coefficient and the increase of that coefficient caused by rising moisture content is several times higher than that resulting from ambient temperature change. However, the same material subjected to slow drying over a long time recovers heat conductivity equal to that of a new product. In standard laboratory conditions, i.e. at a temperature of $(23 \pm 2)^{\circ} \mathrm{C}$ and relative humidity of $(50 \pm 5) \%$ drying process is very slow, showing noticeable effects only after 42 days, and final values after so long as 280 days. The rate of change in the thermal conductivity during the drying process for some EPS boards is shown in fig. 6 and the drying procedure for a selected EPS board in fig. 7. It should be emphasized that drying the product completely in use conditions is very hard. 


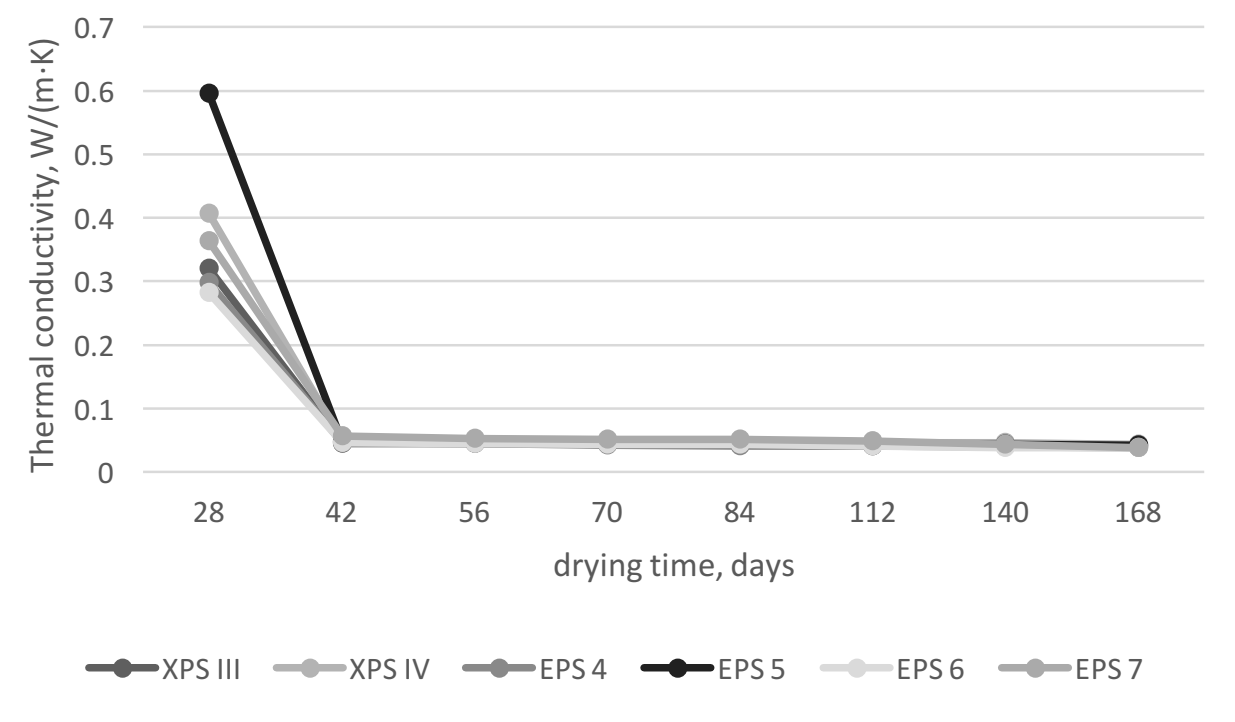

Fig. 6. Change of the thermal conductivity in the process of drying EPS boards in laboratory conditions after soaking and freeze-thaw cycles.

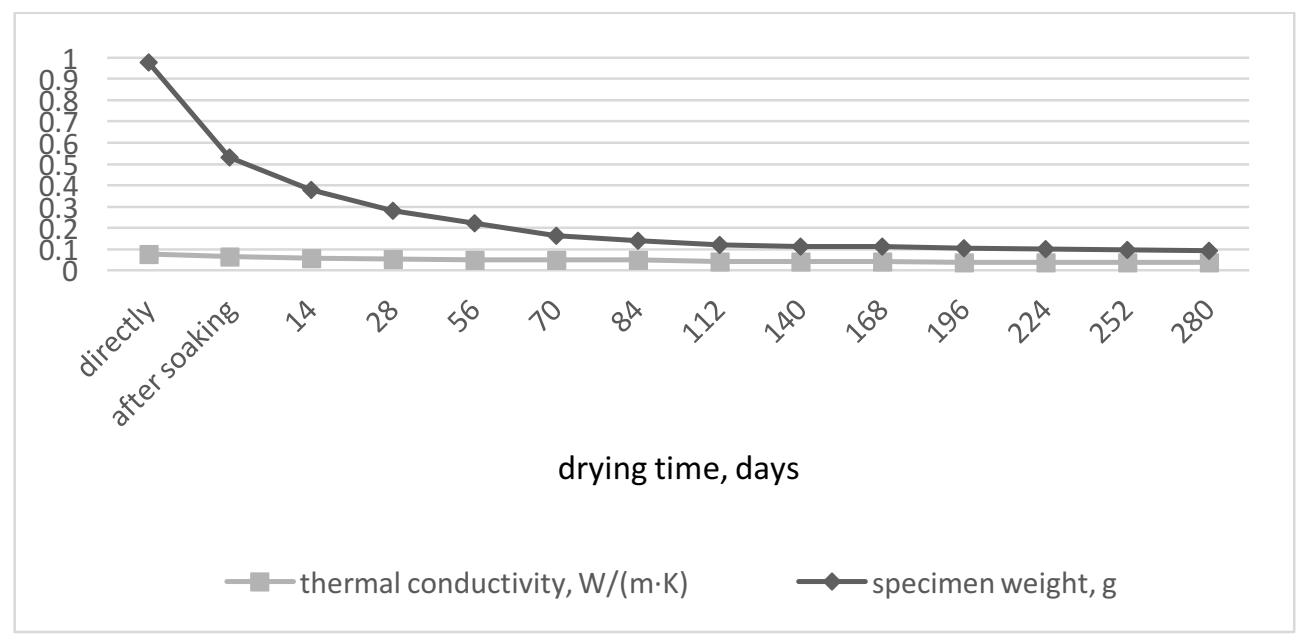

Fig. 7. Relation between change of mass in the drying process and the corresponding thermal conductivity for one of the samples (labelled as EPS 7).

Inspections of buildings suggest that the water absorbing process in thermal insulation layers of inverted roofs/terraces made of materials with properties compliant with ETAG $031[2]$ requirements typically starts after 5 to 10 years of use.

\section{Conclusion}

Test results discussed in this article suggest conclusions described below:

$>$ following immersion of EPS and XPS boards in water, the most significant increase in moisture content takes place in first days of soaking and stays mostly consistent in subsequent days. Freezing and thawing the boards, irrespective of the initial water absorption, causes constant and considerable increase of moisture content, 
the tests did not show any relation between the initial water absorption following immersion

in water and that reached after applying the freeze-thaw cycles. With the initial absorption being similar, the moisture content increase curves have different shapes,

$>$ lack of relation between water absorption after 28 days of immersion and that caused by cyclic freezing and thawing limits options for assessment of fitness of polystyrene boards on inverted roofs/terraces based on declared water absorption in longterm total immersion,

$>$ comparison of influence of moisture content on heat conductivity allows to conclude that moisture content has a considerable effect on the $\lambda$ coefficient and the increase of that coefficient is tied to increase of moisture content. Wet insulation material left to dry on its own will recover its initial coefficient value.

The paper was prepared within the statutory research work at ITB (Warsaw - Poland), $\mathrm{n}^{\mathrm{o}} \mathrm{NZM}$ 042/2017 “Assessment of durability of inverted roof's and terrace's covering systems in the aspect of determining the optimal economic level of their application" and with the technical support of Iwona Komosa and Aldona Wasilewska

\section{References}

1. K.Firkowicz-Pogorzelska, B.Francke, , Projektowanie i wykonywanie stropodachów o odwróconym układzie warstw. Poradnik (ITB, Warszawa, 2012)

2. Etag 031- European Organisation for Technical Approvals, Guideline for European Technical Approval of Inverted Roof Insulation Kits Part 1: General (2010)

3. J.A.Pogorzelski, K.Firkowicz-Pogorzelska, A.Bobociński, Prace Instytutu Techniki Budowlanej - Kwartalnik 3, 139 (2006)

4. D.Zirkelbach, B.Schafaczek, H.Künzel, XII DBMC International Conference on Durability of building Materials and Components 1, (2011)

5. H.Künzel, K.Kiebl, CIB W40 Proceedings Kyoto 1 (1997)

6. H.Künzel, IBP-Mitteilung, Bieten begrunte Umkehrdacher einen dauerhaften Warmeschutz 271 (1995)

7. H.Künzel, IBP-Mitteilung, Feuchteverhalten von Umkehrdachern mit massiven Deckschichten 295 (1996)

8. J.Potter, H.Evans, A review of recent guidance on inverted roof construction, 11, 1 (2001) 